\title{
Anti-CD137 Agonistic Monoclonal Antibody ADG106
}

National Cancer Institute

\section{Source}

National Cancer Institute. Anti-CD137 Agonistic Monoclonal Antibody ADG106. NCI

Thesaurus. Code C160715.

\begin{abstract}
A human agonistic monoclonal antibody targeting CD137 (4-1BB; tumor necrosis factor receptor superfamily member 9; TNFRSF9), with potential immunostimulating activity. Upon administration, anti-CD137 agonistic monoclonal antibody ADG106 binds to and activates CD137 expressed on a variety of leukocyte subsets including activated Tlymphocytes and natural killer (NK) cells. This enhances CD137-mediated signaling, induces cytokine production and promotes T-cell mediated anti-tumor immune responses. CD137, a surface glycoprotein of the tumor necrosis factor receptor superfamily, is an inducible costimulatory receptor that plays a key role in T-cell proliferation, survival and cytolytic activity.
\end{abstract}

